\title{
UNUSUAL PRESENTATION OF A HYDATID CYST: A CASE REPORT
}

\author{
SATTAR A ${ }^{1}$, NAHAR N $^{2}$, RAHMAN MM ${ }^{3}$, ANWAR ASMT ${ }^{4}$, HOSSAIN A ${ }^{5}$, ANWAR ASMT ${ }^{6}$
}

\begin{abstract}
:
Hydatid disease is a parasitic disease, which is most commonly caused by Echinococcus granulosus. It is endemic in many parts of the world. However, Hydatid disease can occur in almost any part of the body. Isolated omenal hydatid cyst is one of the least common sites. A case of very unusual omental hydatid cyst is presented here which was diagnosed in the Department of Radiology \& Imaging, Dhaka Medical College Hospital, Dhaka, and subsequently confirmed by histopathology.
\end{abstract}

Key words: Hydatid cyst, omentum.

J Dhaka Med Coll. 2013; 22(2) : 216-218.

\section{Case report:}

A previously healthy 38 years old male patient was admitted to DMCH with abdominal discomfort, gradual distention of abdomen and fever. There was no history of abdominal surgery or trauma. The physical examination of the abdomen revealed hepatomegaly and a painless, firm, mobile abdominal mass. Elactuation test of the mass was positve. laboratory tests showed eosinophilia $(7 \%)$ and raised ESR (120 $\mathrm{mm}$ in $1^{\text {st }}$ hour). Plain $\mathrm{x}$-ray of abdomen and chest showed no abnormality. Ultrasound and computed tomogrophic scans of the abdomen revealed a huge complex soft tissue mass with innumerable small cysts (honeycomb appearance) seen in the epigastrium mostly on the left side and left hypoechondrium. Moreover, CT scan showed that the mass was separate from liver, pancreas and kidney rather displaces them. After intravenous contrast, mild enhancement of the cyst wall and internal soft tissue component was noted. Radiological differential diagnoses included pancreatic pseudocyst, hydatid cyst and intra abdominal abscess. With these suspicion antibody test for Echinococcus was done and found positive. Hence, the final diagnosis was intraperitoneal hydatid cyst.

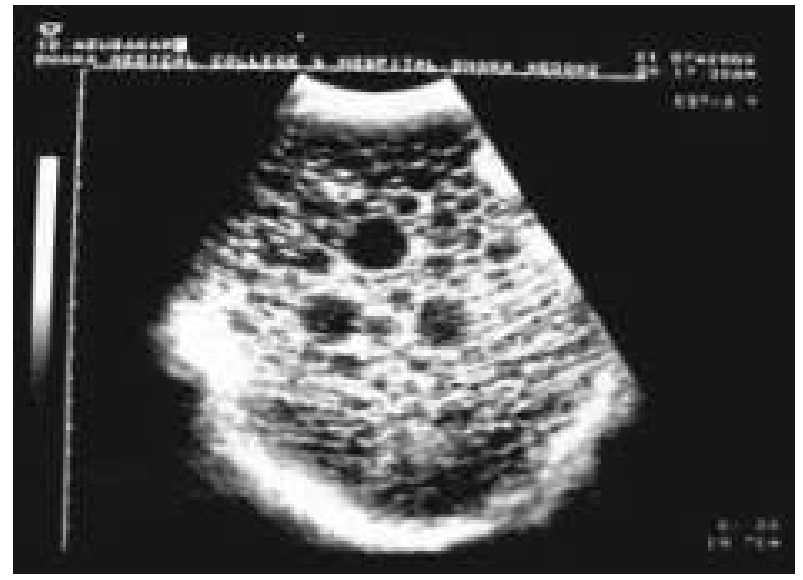

Fig. 1. Sonograhic image revealed a huge complex soft tissue mass with innumerable small cysts (honeycomb appearance).

1. Dr. Asifa Sattar, Assistant Professor, Department of Radiology \& Imaging, Sir Salimullah Medical College, Dhaka

2. Dr. Nazmun Nahar, Assistant Professor, Department of Radiology \& Imaging, Dhaka Medical College, Dhaka.

3. Dr. Md. Mizanur Rahman, Associate Professor, Department of Radiology \& Imaging, Dhaka Medical College, Dhaka

4. Dr. ASM Tanim Anwar, Medical Officer, Department of Medicine, Dhaka Medical College, Dhaka

5. Dr. Anwar Hossain, Assistant Registrar, Department of Medicine, Dhaka Medical College, Dhaka

Correspondence : Dr Asifa Sattar, Assistant Professor, Department of Radiology \& Imaging, Sir Salimullah Medical College, Dhaka. 


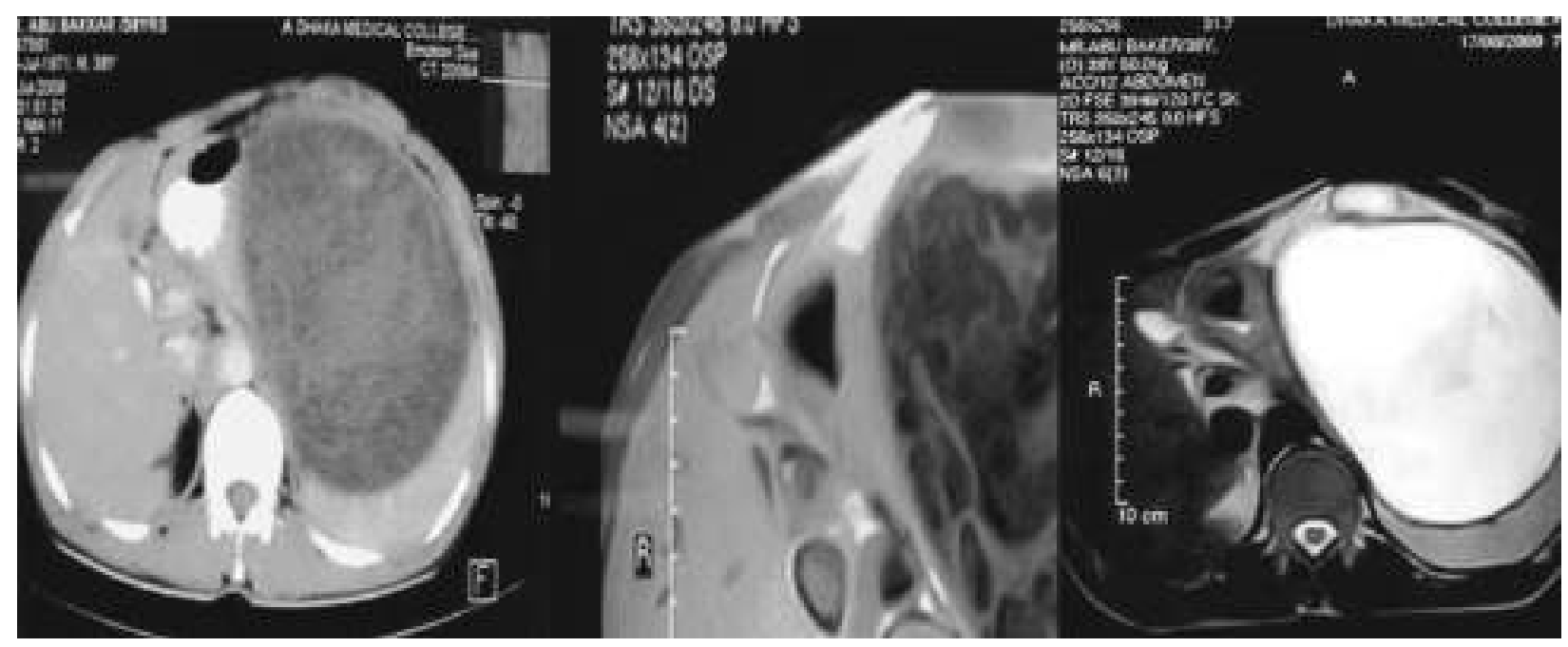

Fig.-2. CT scan revealed that mass is separate from liver, pancreas and kidney rather displaces them. After intravenous contrast, mild enhancement of the cyst wall and internal soft tissue component was noted.

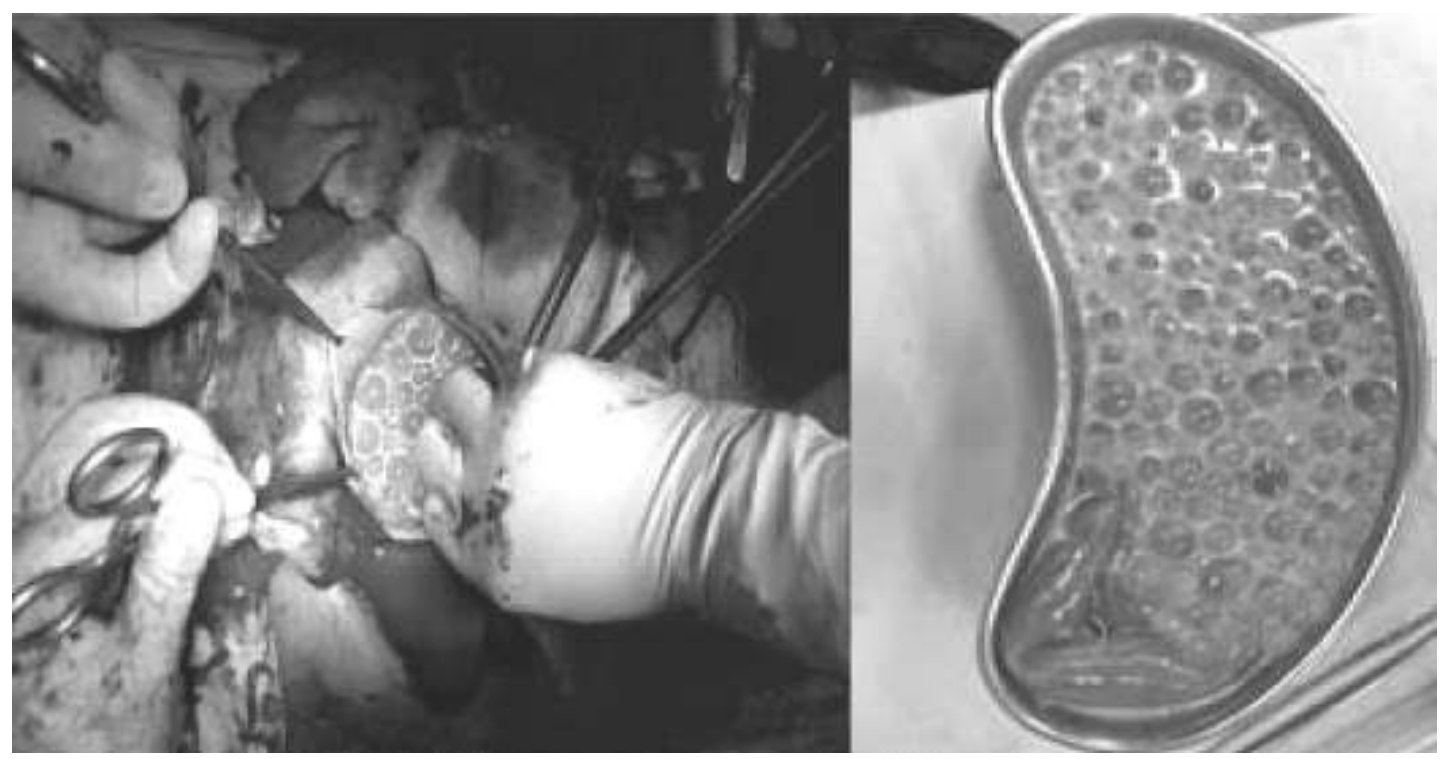

Fig.-3: Peroperative findings of the patient.

\section{Peroperative findings:}

Abdominal exploration revealed a cystic mass. A large cyst was found attached to the peritoneum covering the left lobe of liver and occupying lesser sac. There was no invasion of surrounding tissue. After giving an incision on cyst multiple daughter cysts and pus mixed fluid was found which were sucked out and cyst wall of mother hydatid cyst came out. Cyst wall sent for histopathology and diagnosis was confirmed.

\section{Discussion:}

Hydatid disease is a unique parasitic disease that is endemic in many parts at the world. It is caused by Echinococcus infection. Peritoneal hydatid cysts are almost always secondary to hepatic involvement. Few unusual cases of primary peritoneal involvement have been described $^{1}$. Diagnosis of hydatid cyst can be achieved by clinical findings, serological tests and imaging methods such as plain radiography, ultrasonography, computed 
tomography and magnetic resonance imaging. The imaging methods depend on the involved organ and the growth stage of the cyst ${ }^{1}$.

Radiologic findings: Hydatid cysts are classified into four types on the basis of their appearance:

Type I: It appears as a well defined anechoic mass with or without hydatid sand and septa in sonography (Fig.1). Rolling the patient during evaluation disperses the sand, creating small echogenic foci or falling snowflake. However, in $\mathrm{CT}$, this appears as well defined water attenuation mass (Fig.2a). Frequently the septa and cyst wall enhances after injection of contrast material in CT and MRI which helps to differentiate type-I hydatid cysts from a simple liver cyst. MR imaging may show hypointensity on T1W (Fig. $2 \mathrm{~b}$ ) and marked hyperintensity on T2W (Fig.2c) images. A low signal internsity rim ("rim sign") may also be evident on T2W MR (Fig.2c).

Type II: It is cyst with daughter cyst(s) and matrix complete detachment of the membranes inside the cyst has been referred to as the 'water lily sign' on sonography.

It is devided into three stages-

i) Type IIA Lesions contains round daughter cysts arranged at the periphery,

ii) Type IIB Multiple cysts within a single capsule give rise to a "racemose" or "wheel spoke" appearance Sometimes, multivesciculr cysts manifest a honeycomb pattern, and

iii) Type IIC Round or oval lesions with scattered calcifications representing degeneration of old cyst.

Type III (Calcified cyst): Type III lesions are dead cysts with total calcificaion. They demonstrate strong posterior shadowing at US Manifest as round, hyperatteneuating margins at CT which is hypointense at MR imaging.

Type IV (Complicated hydatid cysts): Complications of hydatid cysts include rupture and superinfection and may be seen in both type I and type II hydatid cysts. Peritoneal hydatid cyst may be asymptomatic or may cause abdominal pain, distension or present as a visible abdominal mass. Serological tests may be useful in the diagnosis, but they are not $100 \%$ reliable $^{3}$.

The differential diagnosis should include other cystic lesions such as mesenteric cyst, choledochal cyst, pancreatic cyst. Choledochal cyst, pancreatic cyst, pseudocyst, gastrointestional duplication cyst and ovarian cyst ${ }^{4}$. If the cyst is complicated differential diagnosis should included intrabdominal abscess, haematoma and ascites. Carefu levaluation of the location of the mass, organ relationship and tissue characteristics, along with clinical parameters, witll be useful in the differential diagnosis ${ }^{3}$. The treatment peritoneal/omental cyst is mainly surgical. Cystectomy is usually indicated even if the patient is asymptomatic because of possibility of torsion, rupture bleeding and infection. Rupture of a hydatid cyst may lead to anaphylactic shock and there is also the risk of recurrence of the disease. Therefore, to avoid accidental spillage of the parasite during the operation and to perform a complication free procedure, knowledge of the preoperative diagnosis is important ${ }^{4}$. A definitive diagnosis is mode according to histopathological findings. In our case a total cystectomy was performed. Histopathological examination confirmed the diagnosis of hydatid cyst in which a scolex was attached to the germinative layer.

\section{Conclusion:}

The diagnosis of omental hydatid cyst should be considered as a differential diagnosis of cystic lesion of the abdomen particularly in endemic areas. The differential diagnosis can be made easily owing to characteristic appearance of daughter cyst.

\section{References:}

1. Polat P, Kantarci M, Alper F, Suma S, Koruyucu MB, Okur A. Hydatid disease from head to toe. Radiographics 2003; 23: 475-94.

2. Pedrosa I, Saiz A, Arrazola J, Ferreiros J, Pedrosa CS. Hydatid disease: radiologic and pathologic features and complications. Radiographics 2000; 20: $795-817$.

3. Sekmenli T, Koplay M, Sezgin A. Isolated omental hydatid cyst: clinical, radiologic, and pathologic findings. J Pediatr Surg 2009; 44(5): 1041-3.

4. Kalovidouris CA, Pissiotis C, Pontiflex G, et al. CT characterization of multivesicular hydatid cysts. J Comput Assist Tomogr 1986; 10: 428-31. 